\title{
CD1 Expressing Cell Measurement
}

National Cancer Institute

\section{Source}

National Cancer Institute. CD1 Expressing Cell Measurement. NCI Thesaurus. Code C103364.

A count of the CD1 expressing cells per unit of a biological specimen. 